\title{
Internal Carotid Nerve Plexus
}

National Cancer Institute

\section{Source}

National Cancer Institute. Internal Carotid Nerve Plexus. NCI Thesaurus. Code C52746.

A series of autonomic nerves around the internal carotid artery. 